\title{
Thematic Section
}

\section{Understanding and Addressing Inequalities in the Context of Structural Transformation in Africa: A Synthesis of Seven Country Studies}

DZODZI TSIKATA

\begin{abstract}
This article features the analysis and comparative assessment of a set of studies on the dynamics and drivers of and policy responses to inequalities in the context of structural transformation in Africa, including an overview paper, seven country studies, and a paper on gendered assets inequalities, all published in abridged versions in Development 57(3-4) (Armah et al., 2014; Ariyo and Olaniyan, 2014; Bunwaree, 2014; Diene, 2014; Kedir, 2014; Omilola and Akanbi, 2014; Osei-Assibey, 2014; Owiti, 2014; Wanjala, 2014). Drawing from these studies, it explores the conceptual frameworks, the key domains and the main drivers of inequalities. It further examines recent policy interventions and outlines policy implications, providing a preliminary basis for setting an agenda for research and advocacy to support African and country efforts to tackle the deepening inequalities and achieve structural transformation.
\end{abstract}

KEYWORDS income inequalities; social inequalities; political inequalities; Africa 2063; gender inequalities; structural transformation

\section{Introduction, context and scope of the assessment}

There are two distinct but interconnected questions of Africa's development that are currently very topical in the development discourse. These are as follows: (a) how to address the persistent and worsening problem of inequalities in access to resources and opportunities and in development outcomes? and (b) how to reactivate and complete the unfinished agenda of structural transformation of African economies and societies? In Africa, the growing inequality in income, wealth, access to social services and decent employment in the midst of consistent economic growth in the last decade has become a matter of grave concern (Armah et al., 2014). Seven of the ten most unequal countries in the world - Namibia, Comoros, South Africa, Angola, Botswana, Lesotho and Swaziland - are in Southern Africa. Many countries are confronted with striking increases in inequality, such as South Africa and Central African Republic, where the Gini coefficients increased from 58 to 67 (2000-2006) and from 43 to 56 (2003-2008), respectively (Omilola and Akanbi, 2014; Armah et al., 2014). ${ }^{1}$ 


\section{Tsikata: African Inequalities and Structural Transformation}

Rising inequalities have also been recognized as a global issue. For example, a Credit Suisse study finds that 10 per cent of the global population holds 86 per cent of the assets in the world while the poorest 70 per cent (more than 3 billion people) holds 3 per cent (Credit Suisse, 2013). 1 per cent of households owns 46 per cent of the world's wealth and the bottom half of the world's population combined owns less than the 85 richest people in the world. The wealth of the one per cent of richest people in the world amounted to $\$ 110$ trillion, almost 65 times the total wealth of the bottom half (Oxfam, 2014). ${ }^{2}$ In response to research and effective advocacy by a global coalition of intellectuals, civil society activists and policymakers, the recently adopted Sustainable Development Goals have devoted one stand-alone goal to reducing inequality between and within countries (Goal 10) in addition to the goal on achieving gender equality and empowering women inherited from the MDGs framework (Goal 5).

Structural transformation is a key pillar of Agenda 2063, which was adopted by African Heads of State and Government during the celebrations of the 50th Anniversary of the OAU. ${ }^{3}$ It was born out of concern that a relatively long period of sustained and rapid economic growth failed to translate into the creation of decent employment and the balanced and sustainable transformation of African economies. Instead, many African economies continue to experience stagnation in agriculture, declining levels of industrialization and growth in informal services.

That these two questions have become topical at this juncture is not accidental, and is in fact opportune. Studies have suggested that without structural transformation of Africa's low-productivity agrarian economies to mixed economies with healthy agrarian, industrial and service sectors, efforts to deal with inequalities in development outcomes can only be cosmetic. At the same time, there is evidence that structural transformation will not produce just and equitable economies and societies unless addressing inequalities constitutes an integral part of the agenda of structural transformation (Armah et al., 2014).
A broad-based consortium of African governments, United Nations agencies, research institutions and civil society groups collaborated in 2014 to organize a region-wide conference on tackling inequalities and promoting structural transformation in Africa as two integral aspects of Africa's development agenda. ${ }^{4}$ This was to influence UN processes to fashion the sustainable development agenda and also to establish research, policy and advocacy agendas on structural transformation in Africa. Several background papers were commissioned or adapted for the conference. These included seven country studies (Ethiopia, Ghana, Kenya, Mauritius, Nigeria, Senegal and South Africa) on the dynamics and drivers of the various domains of inequalities in Africa, policy responses and recommendations for the future, an overview paper on structural transformation and inclusive development from the United Nations Economic Commission for Africa (UNECA), and a paper on gendered assets inequalities in Africa.

This article synthesizes the country studies, the overview paper and the paper on gendered assets inequalities. The country studies cover countries with different degrees of income inequalities ${ }^{5}$ and variations in other characteristics. For example, Ethiopia is largely agrarian and rural (only 17 per cent of its population lives in urban areas), while South Africa and Mauritius are the most industrialized and urbanized of the seven. Kenya and Nigeria have significant industrial components, while Ghana and Senegal are largely agrarian economies that are increasingly dominated by largely informal service sectors. Thus, the majority of the countries in the study cannot be said to have undergone structural transformation, in spite of the changes they have experienced in the contribution to GDP of their various sectors over the years.

The seven papers are not perfectly comparable. The way the brief was interpreted depended on data availability, the disciplinary orientation of authors, their sense of which inequalities were most important, and in cases where already commissioned papers were adapted, on their original terms of reference. The differences in data availability were particularly challenging, as 


\section{Development 58(2-3): Thematic Section}

not all the relevant data existed for all the countries. Also, the existing data had been collected over different time periods. Only a few countries had longitudinal data-sets. For example, Ethiopia had the Ethiopian Rural Household Survey (ERHS) and the Ethiopian Urban Household Survey and South Africa also had panel data. Senegal on the other hand did not have panel data on households and therefore had to use surveys reported in 1995 and 2001 (Enquete Senegalaise de Manages-ESAM I and ESAM II).

There were also differences in the kind and degree of detail in data collected on any particular inequality. Some countries had provincial breakdowns (South Africa), while other countries focused on rural-urban differences (Ghana). The differences in data availability also affected the choice of indicators that were used as proxy for the different domains of inequalities. Thus while some papers focused on income in analyzing economic inequalities, others combined income with employment (Ethiopia) or with employment and assets inequalities (Ghana). The situation with social inequalities was no different. Some studies used health insurance for the health indicator (South Africa and Ghana), while others used access to health facilities and skilled personnel, malnutrition and weight, HIV/AIDS prevalence (Senegal) and maternal mortality (Ethiopia). These data limitations indicate an urgent agenda for African countries to agree on indicators as well as modalities for data collection that can support a regional agenda for monitoring and addressing inequalities and structural transformation.

The article approaches the challenges of data by using what data are presented as indicative/ illustrative of the dynamics of particular domains of inequalities with the understanding that the absence of a discussion of a certain domain of inequalities in a particular country does not imply that there is no issue with that domain in that country.

The article has five broad segments. The introduction is followed by a discussion of the conceptual frameworks and key domains of inequalities within the various case studies. The 208 third section is discussion of the nature and drivers of inequalities as revealed by the data in the country studies. The fourth examines policy interventions, followed by a consideration of policy implications for the African agenda for Structural Transformation.

\section{Framing inequality and its domains}

\section{Deepening the challenge on dominant applications of Kuznets' thesis}

All nine studies consider inequalities as a problem requiring policy intervention. Thus, they take as their point of departure recent challenges to the dominant interpretations of Kuznets' thesis on economic growth and inequalities. Kuznets argues that inequality is one of the costs of development and growth (Kuznets, 1955). His thesis is that inequality is mostly low at the early stages of development and increases as economies grow and advance from being agricultural to becoming industrial. With sustained development, and upon reaching a certain stage of growth and transformation, inequalities begin to reduce (Kuznets, 1955, in Kedir, 2014; Armah et al., 2014). Based on this, some have argued that although economies of scale and agglomeration resulting from structural transformation can decrease absolute poverty, they are inevitably accompanied by rural-urban/regional inequality (Fox and Pimhidzai, 2011).

In the context of the industrial revolution, some countries in Western Europe and America conformed to Kuznets' thesis, which has been rendered as a curve. However, some more recent experiences of structural transformation have failed to confirm the Kuznets' curve (Armah et al., 2014). Several studies on the relationship between inequality and economic growth and transformation have yielded mixed results, with some studies reporting a positive relationship (Okun, 1975) and others reporting a negative relationship (Alesina and Rodrik, 1994; Persson and Tabellini, 1994; Berg et al., 2012).

With the renewed interest in income distribution, there have been several re-examinations of Kuznets' theory. For example, Lee et al. (2015) have argued that the long-held view that 


\section{Tsikata: African Inequalities and Structural Transformation}

inequality was an inevitable outcome of structural transformation had been based on a partial reading of Kuznets. This is because his turning point, beyond which inequality begins to decline, was not economic or based on the natural progression of an economy or the unseen hand of the markets. It was instead due to political and policy choices propelled by the growing power of the urban working classes. Therefore, reducing inequalities in the context of structural transformation is not automatic. Rather, it is a matter of social and political choice, and robust policies. The empirical evidence supports this view in showing that much depends on country-specific conditions and national policies (UNDESA, 2013).

The UNECA study also provides concrete proof of the policy basis of inequalities in discussing inequality trends in three countries undergoing structural transformation - Brazil, India and China. The paper argues that while Brazil continues to experience 'record-high levels of inequality', its recent economic growth has improved the situation of poor people partly because of improvements in education and labour market conditions, as well as expanded social assistance programmes such as cash transfers. China and India, on the other hand, have experienced rising inequalities in spite of high levels of growth. The paper also attributes the high levels of inequalities in Latin American countries, which are mostly middle income ones, to a combination of unequal distribution of land and education, high returns to skilled workers, high fertility rates in poorer households and regressive public spending. Countries such as Argentina, Brazil, Ecuador, Uruguay and Paraguay are said to be successfully tackling inequalities by addressing some of these problems (Armah et al., 2014).

The argument about the policy basis of inequalities is important in thinking about how to approach structural transformation in ways which ensure equity and sustainability in outcomes. It is a welcome departure from the approach that considers inequalities to be inevitable in the context of structural transformation. While there is some discussion of the positive effects of income inequality (Kedir,
2014), ${ }^{6}$ the overwhelming majority of recent commentary has drawn attention to the negative effects of income inequality such as credit rationing, collateral requirements which restrict investment opportunities of the poor, and the risk of violence, social unrest and insecurity (Kedir, 2014).

Several, though not all, of the country studies distinguish between poverty and inequalities by pointing to the paradox of progress in poverty reduction combined with growing inequalities. Both the South African and Ghanaian studies make this point, arguing that while there is evidence of poverty reduction after decades of high levels of economic growth, inequalities have increased sharply over the same period. Both studies also suggest that there are linkages between inequalities and poverty (Osei-Assibey, 2014; Omilola and Akanbi, 2014). The South African study notes that the South African economy is facing a triple challenge of high levels of poverty, unemployment and inequality, and that high levels of unemployment and inequality could deepen poverty. It argues that the Millennium Development Goal (MDG) of reducing poverty is flawed in concentrating on achieving high growth and neglecting questions of how growth is distributed. This has led to poverty reduction due to rising incomes, but to increased inequalities that have dampened the impact of growth on poverty reduction (Omilola and Akanbi, 2014). The Ghanaian and Ethiopian studies make a similar argument, that growing inequalities are undermining the progress of poverty reduction. As the Ethiopian study notes, 'inequality weakens the poverty reducing capability of growth' (Kedir, 2014: 2; see also OseiAssibey, 2014 for similar arguments).

\section{Recognizing different domains of inequality and their linkages}

There are three main domains of inequalities economic, social and political - identified by the country studies. The UNECA study formulates this slightly differently when it argues that 'inequality is multi-dimensional with economic, social and political underpinnings' (Armah et al., 209 


\section{Development 58(2-3): Thematic Section}

2014). This formulation is useful in highlighting the point that inequality is one phenomenon with different dimensions. However, there is merit in discussing the different domains or dimensions of inequality. Economic inequality is mainly defined in relation to income and its distribution between groups. Armah et al. (2014) have a broader definition which has three measures - income, assets $^{7}$ and access to productive employment. It has been pointed out that income, wealth and consumption have dominated inequality discussions because they directly contribute to the welfare of individuals and families, define people's life prospects, and the future of their children. As well, they shape other dimensions of inequality, particularly access to social services (Armah et al., 2014). The addition of productive employment to the definition improves our understanding and appreciation of economic inequality, as employment is an important source of income and assets.

One critical dimension of income inequality is missing from all the papers. This concerns how total income is distributed between capital and labour. Increasingly, it is being argued that how total income is distributed between individuals and households is only part of the story of income inequalities, and therefore, focusing solely on this aspect will not address inequalities fundamentally, and would increase the costs of addressing personal income distribution (Mkandawire, 2013; Lee, 2015). While this issue is beyond the scope of this synthesis, it requires attention in future work on inequalities.

The social dimension of inequality is associated with differences in access to basic social services such as education, health care, housing, energy, water and sanitation, while political inequalities refer to the differences in the possession and allocation of political resources in society such as voice, participation, access to policymaking institutions and processes, and government responsiveness (Armah et al., 2014). See also Neckerman (2004) for a discussion of the consequences of social inequalities.

The value of identifying different domains of inequality enriches and deepens our understand210 ing of this most complex subject beyond the traditional focus on income inequality and lays bare the linkages and contradictions among the different dimensions of inequality. Several of the studies discuss and demonstrate this in more or less detail. As one study argues, the fact that the amount of wealth and income a person has can determine their access to social goods such as housing, healthcare, education and other social services demonstrates the close link between economic and social inequalities (Armah et al., 2014). In the same vein, there are linkages between economic and political inequalities. Whereas inequalities in economic resources can affect the ability of citizens to influence government policies, elites in politics can also enact policies that will further improve or benefit already advantaged groups (Armah et al., 2014). For example, the Kenya study shows how the monopoly of political power allows certain groups to control economic and social power or how economic inequalities disable groups from access to social resources and thereby promote inequalities in the social domain. As the study argues,

'economic activity generates the resources with which to invest in social goods, but the way in which these resources are accessed, harnessed and deployed have a huge impact on the quality of life of the majority, which decision is largely affected by the political context' (Owiti, 2014).

Similarly, in relation to gender, inequality in one domain influences inequalities in other domains. For example, imbalances in access to education and formal institutions of power are reflected in inequalities in economic power (Wanjala, 2014). The Kenya study also found that women own less than 5 per cent of land as a result of institutional and legal barriers, and this in turn affects their access to financial services (Owiti, 2014).

At the same time, all three domains of inequality do not move in the same direction. For example, the experiences of women and ethnic minorities in some countries suggest that social and political exclusion can go hand in hand with reductions in economic inequalities. Thus women, regardless of economic status, can experience social and political exclusion. On the other hand, impressive 


\section{Tsikata: African Inequalities and Structural Transformation}

progress in increasing the number of women holding parliamentary seats in African countries such as South Africa has not gone hand in hand with a reduction in wage inequalities between men and women. Thus, tackling one domain of inequality does not necessarily assure progress in other domains. Even within the same domain, tackling inequality in one area does not guarantee progress in others. The promotion of gender parity in primary school enrolment has not translated into addressing inequalities in women's access to higher education or their access to paid nonagricultural work (Armah et al., 2014).

The three domains were discussed along several axes in the country studies - classified by wealth and income; type and sector of employment, gender, age - children, youth and aged; spatial/geography - rural/urban, ethno-regional, ecological zones - as they affect individuals (vertical inequalities) and groups based on identities such as gender, ethnicity and religion; and in particular locations (horizontal inequalities). A few studies discuss spatial inequality as a domain (Kedir, 2014), or a dimension of the three domains (Osei-Assibey, 2014).

A complication in accounting for inequalities is how the domains and axes intersect. This can be clearly seen in the data on gender inequalities. As the UNECA study notes, gender inequalities intersect with class and geography to disadvantage particular categories of women even more than others. This issue is important in thinking about different kinds of vertical and horizontal inequalities, as certain persons carry more disadvantages than others within particular social groups.

\section{Identifying the drivers of inequality}

The studies identify the drivers of inequality, in keeping with the approach to inequality that suggests that it is not inevitable or accidental. Several drivers of inequality have been identified in the studies and other literature, and these include historical factors, the inter-generational transfer of inequalities, contemporary policy failures, socio-cultural practices and political discrimination.
With regard to historical factors, the developmental differences between northern and southern Ghana have been attributed to colonial neglect of northern Ghana (Osei-Assibey, 2014). On the other hand, some of the socio-economic inequalities in countries such as Kenya have been attributed to the establishment of settler economies, which are some of the most unequal, or the emergence of a land-owning capitalist group, as a result of the dismantling of settler estates through africanization programmes in the early postcolonial periods (Owiti, 2014).

History is also important with regard to another driver of inequalities. This concerns the inter-generational transfer of disadvantages. Children and adolescents from the poorest households are three times more likely to be out of school than children from the richest households are. As well, children from the poorest households are twice as likely to be stunted as children from the richest households, and as stunting affects educational prospects, this is likely to be a factor in inequalities in educational attainment (Armah et al., 2014). This perpetuates inequality and disadvantage over generations.

Another driver of inequalities is policy failures, inaction or neglect as well as the intended and unintended consequences of policies which create some of the binaries in the three domains of inequalities known as axes of inequalities. For example, decades of economic liberalization policies have resulted in the expansion of informal work and the increase in temporary, part time, sub-contracted jobs and self-employment and a contraction of formal work. As much as informal work becomes the norm, so is low productivity with underemployed, vulnerable workers in precarious labour conditions. This creates conditions for economic inequality based on access to decent employment (Armah et al., 2014). Related dichotomies such as rural and urban, export commodities-food crops dependent also structure inequalities in work and income. Inequalities have also been attributed to the emergence of finance capital as a key player in the global political economy. It has resulted in a small network of financiers who own much of the new wealth. It has been argued that investment 211 


\section{Development 58(2-3): Thematic Section}

decisions of this small group sometimes have more critical impact than the economic policies and interventions of national governments (Armah et al., 2014).

Sources of socio-economic power, which also create inequalities, are the unequal distribution of value producing resources - labour, animals, land, water, natural resources, technologies, financial power and weapons of coercion (Armah et al., 2014), distance from or proximity to power centres and the governing elite (Owiti, 2014). Also important are differences in access to the state, educational attainment, geography, demography, occupation, gender, race and class.

As regards political inequality, its main drivers have been identified as ethno-regional patronage, crony capitalism and political exclusion (Owiti, 2014).

Those who suffer most from inequalities are uneducated women living in poverty, slum dwellers, pastoralists living in drought prone areas, subsistence farmers, the landless, the disabled, and those with fragile livelihoods or who belong to indigenous minorities (Owiti, 2014).

Discriminatory cultural practices are also an important driver of inequalities, particularly gender inequalities. Examples of such practices include early marriages, which undermine women's education, and the gender division of labour, which assigns women the bulk of reproductive work that remains unpaid and undervalued (Owiti, 2014). An institutional approach to gender inequalities argues that the state, the family, the community and the market condition women's and men's ability to accumulate wealth, their access to land and natural resources, the size and profitability of their businesses, and their access to finances and political capital (Wanjala, 2014).

\section{Inequality of opportunities versus inequality of outcomes}

What kinds of inequalities should be the subject of policy interventions? This question is examined extensively by the UNECA study, which distinguishes between inequality in outcomes and inequality in opportunities, and more controversially, between inequalities attributable to effort and those attributable to opportunities or circumstances. The study argues that

there is an increasingly widespread normative view that it is inequality of opportunity rather than inequality of outcomes, which should inform the design of public policy. It is thought that public action need not necessarily aim to eliminate all outcome inequalities, but may be justified in seeking to reduce those that arise from unequal opportunities' (Armah et al., 2014: 11).

This position is based on the view shared by some influential economists that inequality of outcomes is ethically acceptable if it arises from individual choices, but unacceptable if it is from 'opportunities, capabilities and circumstances' (Armah et al., 2014: 11).

This is a troubling argument on a number of grounds. First, the definitions of 'effort' and 'opportunity/circumstance' are problematic. Effort is defined as encompassing factors over which individuals have a measure of control or a certain responsibility, such as the number of years spent in school and the nature of studies undertaken, or the number of hours of work, etc. Circumstances, on the other hand, are defined as factors that individuals have no control over, such as race, gender, physical conditions, family background, etc. These factors are generally predetermined (Armah et al., 2014: 9).

The use of the phrases and words such as 'a measure of', 'a certain' and 'somehow' suggests that there is unsureness about the claims that individuals have control and choice in the matters being referred to. This is precisely the difficulty with distinguishing effort from opportunity/circumstance. While we can assume that everyone, including those who experience economic, social and political inequalities, has agency which they exercise within the limits of their circumstances, it is a different matter to make a clear distinction between inequality outcomes which are the result of effort and those which are due to circumstances. Since educational choices are made for minors by their 


\section{Tsikata: African Inequalities and Structural Transformation}

parents and guardians, circumstances or opportunities are likely to be as critical as effort in educational outcomes. Regarding educational outcomes based on effort and subject choices, there are many examples of mediocre students who went to the best schools and went on to be employed in the best jobs because of family connections. Furthermore, the 'education as effort and choice' arguments ignore the complicated structures of inequality and its systemic character in paying too much attention to individual effort.

Thus, while it may be theoretically possible to make such a distinction, how to make this determination among the vast numbers of people experiencing inequalities is not at all simple, feasible or reasonable in practice. On the other hand, it can have damaging implications for policy efforts to address inequalities, providing ammunition for those who blame inequalities on those who are disadvantaged. The neo-liberal economics literature is replete with such justifications, which are embodied in phrases such as 'perverse incentives' and 'moral hazard', that appear benign, but whose import is to discourage policies that take inequalities seriously.

The success or otherwise of policies which only focus on opportunities will be assessed by both opportunity and outcome indicators because the opportunity indicators are a means to an end, and this creates an integral relationship between opportunities and outcomes. For example, the point of improving access to health facilities is to reduce the time and costs of accessing health care in order to increase coverage, but most importantly to improve key health indicators such as life expectancy and maternal and infant mortality rates. It is pertinent to note that all the background papers and the UNECA paper use both opportunity and outcome indicators in their discussions of inequalities. What this implies is that policy should combine measures that target both opportunities and outcomes. In any case, certain inequalities that are opportunities in some circumstances will be outcomes in others. This is best seen in the relationship between equality and inclusiveness. When growth is achieved through policies that enable people to benefit from the fruits of growth while also taking part in the productive activities that generate that growth, the results are more inclusive and sustainable than policies that only focus on the distribution of growth (Armah et al., 2014).

\section{The nature of inequality in Africa}

\section{Economic inequality}

\section{Indicators and income inequality}

Most of the studies used income, as either the only measure or one of the several measures of economic inequalities. For example, the Ethiopian study used income and land ownership as its two measures of economic inequality. Secondly, most studies used the Gini Index to measure income inequality. For example, the Mauritius study found that income inequalities had increased in Mauritius in the last 16 years (from 0.387 in 1996 to 0.388 in 2006, and to 0.413 in 2012). The study argues that wealth was concentrated in the hands of a few people while the majority of the population lived in poverty, with the disparities between the poor and the rich rising at an alarming rate (Bunwaree, 2014). Similarly, in Nigeria, income inequality had increased, and this was associated with the traditional farming practices usually found in the rural areas (Ariyo and Olaniyan, 2014). The Senegal study reported that the Gini indices were $39.19,38.98$ and 41.3 during the years 2009, 2010 and 2011, respectively, thus showing an increase in income inequality as well (Diene, 2014).

Only the Ethiopian study used both the Atkinson's Inequality Measure ${ }^{8}$ and the Gini Index. The study found more inequality in rural than urban areas using the Atkinson's Inequality Measure and land ownership. However, it found more inequality in urban areas than in rural areas using the Gini Index. The study also found that urban inequality had declined over the last ten years while the gap between urban and rural inequality had also reduced. Consumption expenditures were also higher in urban than in rural areas (Kedir, 2014). The differences in finding between the two measurements raise questions about the two measures that need to be resolved to harmonize measurements. 


\section{Development 58(2-3): Thematic Section}

Another dimension of differences in data collection on inequalities are those which measure differences within particular groups and those that measure differences between groups. All studies used a mix of these measures. For example, the Senegal study compared income inequalities within groups and found higher inequalities within urban areas, particularly in Dakar, than in rural areas, and within certain ethnic groups such as the Wolof and Pulaar ethnic groups. The study also recorded higher income inequalities in male-headed households than in female-headed households (Diene, 2014). The Nigeria study also found that income inequalities were more prevalent in rural than urban settings of Nigeria, and more serious in the northern than southern parts of the country (Ariyo and Olaniyan, 2014). In South Africa, there were severe income inequalities in certain regions of the country (Omilola and Akanbi, 2014).

While in group/location inequalities are interesting and could have policy import, it is more revealing to see the nature of income inequalities between rural and urban areas, among regions, among the different occupational groups, between different racial groups and ethnicities and between men and women. The Kenya study demonstrates the value of this latter approach with a discussion of a 2004 study that found that Kenya's top 10 per cent of households controlled 42 per cent of its total income, while the bottom 10 per cent controlled less than 1 per cent. The study also found significant regional differences in the distribution of poverty, the most extreme being 21.8 per cent for Nairobi and 87.5 per cent for Turkana (SID, 2004, see also Kenya National Bureau of Statistics and Society for International Development (2013) for more recent statistics on inequality in Kenya). Most of the seven country studies found income inequalities between rural and urban areas. In Ghana, there were also economic inequalities between northern Ghana and the rest of the country. ${ }^{9}$ In South Africa, the racial dimensions of income inequalities were pronounced. The majority of the black/African population were in the low-income bracket whereas most of the white population was in the high-income bracket (Omi214 lola and Akanbi, 2014).

\section{Employment}

Several of the studies discussed employment and work as an example of economic inequality. A few studies, however, considered employment as an issue in the social domain (Senegal, Nigeria, Kenya and Ghana). In this synthesis, we discuss work and employment as an indicator of economic inequality. In Africa overall, women and youth had the most limited access to productive employment. In 2012, 84.9 per cent of women were in vulnerable employment as opposed to 70.6 per cent of men. Women were also more heavily concentrated in subsistence agricultural activities, informal work, and unpaid household work which, in addition to low pay, also have poor working conditions. Youth employment in Africa in 2012 was 12 per cent, while adult unemployment stood at 6 per cent (Armah et al., 2014).

The structure of the workforce also revealed inequalities between rural and urban areas, as well as gender and educational differences in most of the countries examined. However, the contours of these differences could be country specific. The unemployment rate in Senegal was 13.3 per cent for women and 7.7 per cent for men (Diene, 2014). In Nigeria, on the other hand, more men than women were unemployed (Ariyo and Olaniyan, 2014). The Kenya study found that in rural areas, female heads of households were more likely to be involved in wage work than male heads ( 31 per cent and 16.8 per cent, respectively). In urban areas, the opposite was true - male heads of households were more likely to be in wage employment than female heads (40.2 per cent and 12.8 per cent respectively) (Owiti, 2014).

In relation to work, an important issue of inequality is the amount of time spent on unpaid productive and reproductive work. This is important because more time on unpaid work limits how much time can be devoted to paid work, and therefore is a factor in income inequality and access to decent work. The Ethiopian study, for example, found that married women worked fewer hours in the labour force and more at home, while married men did the reverse. The average time allocated to housework was $36 \mathrm{~h}$ for women and $7 \mathrm{~h}$ for men, while for market work, the figure was $16 \mathrm{~h}$ for women and $29 \mathrm{~h}$ for men. There were also 


\section{Tsikata: African Inequalities and Structural Transformation}

differences between men and women in whether or not they did housework at all. While almost all women did some housework, about half of men were not involved. When men and women participated in housework, they performed different tasks, with the proportion of women collecting fuel wood and fetching water two times that of men (Kedir, 2014).

Unemployment, a serious problem in several of the study countries, widens inequalities. In Mauritius, there were high rates of unemployment, particularly among the youth and women. This has been attributed to the increasing corruption and collusion between the political and economic elite, jobless and unproductive growth, land speculation, and the sale of lands to foreigners at escalating prices, as well as the nature of FDIS (Foreign Investment from Diverse Sources) (Bunwaree, 2014). In Kenya, people with no education were 1.7 times more likely to have no work than people with secondary education were. On the other hand, urban dwellers with no education were twice as likely to be without work as their rural counterparts were (Owiti, 2014). In Senegal, long-term unemployment (over a year) was a more serious problem for graduate heads of household (74 per cent) than for secondary school graduates (52 per cent), and this was partly on account of the labour market segments occupied by the two groups (Diene, 2014).

High rates of youth unemployment had several ramifications, and these are discussed in a few of the studies. The Senegal study found that high levels of youth unemployment had resulted in illegal migration to Europe, drug use, and trafficking and theft. Many young people had been excluded from the labour markets and some had resorted to the informal sector as a way to survive (Diene, 2014).

\section{Social inequalities}

\section{Indicators}

The studies used a range of indicators to measure social inequality. These included education, health and access to services indicators such as life expectancy, under five mortality, maternal deaths, immunization coverage, health service delivery and labour market participation (Kedir, 2014). Several studies found unacceptable levels of social inequality. For example, the Senegal study described social inequalities as serious, identifying health, education, employment and infrastructure, as key areas of inequality. The study also found that social inequalities had been reinforced by the demographic imbalance of having 62 per cent of the population under 25 years old (Diene, 2014).

The country studies highlighted the connection between economic and social inequalities in several ways. On the one hand, reductions in economic inequalities have failed to translate into lower levels of social inequalities in some cases. For example, the Ethiopian study argued that in spite of the reductions in economic inequalities between rural and urban areas, there remained serious inequalities in service delivery and nonincome and non-expenditure parameters. On the other hand, high levels of income inequality feed into social inequality (Kedir, 2014). For example, the South African study argued that the high levels of income inequality in South Africa had fed into social inequalities in education, health and land ownership. The study highlighted the huge gap between the quality of public and private education systems in South Africa, especially at the basic education level. Consequently, only middle- to high-income earners could access private education with good quality delivery, an obstacle for many South Africans wanting to proceed to higher educational institutions (Omilola and Akanbi, 2014). The Kenyan study also found that income differences were replicated in inequalities in access to education. 50.8 per cent of people in Nairobi had secondary education or higher, compared with 3.3 per cent in Turkana County. The Nairobi figure was 2.2 times the national average (Owiti, 2014).

With regard to education attainment, there were striking racial differences in South Africa. The white population remained the most educated, with the majority holding diplomas, bachelor degrees and higher certificates. The black population on the other hand did not usually 215 


\section{Development 58(2-3): Thematic Section}

complete high school, and had recorded high drop-out rates (Omilola and Akanbi, 2014). The same trend was found in Kenya where only the rich had access to quality education (Owiti, 2014). Also, many children in urban areas in Nigeria were unable to complete primary school. In addition, the children of the rich were usually better educated than those of the poor majority (Ariyo and Olaniyan, 2014). Several of the studies identified gender differences in educational attainment (Ariyo and Olaniyan, 2014; Diene, 2014; Osei-Assibey, 2014).

In Senegal, there were large differences between regions, as well as significant gender disparities in certain regions with respect to primary enrolment. There were also disparities between rural and urban areas in terms of enrolment and literacy. Beyond enrolment, there were striking inequalities in the distribution of educational facilities. For example, the Dakar Region in Senegal had 80 per cent of universities and graduate schools and their students (Diene, 2014).

\section{Health}

The health situation was no different from education. Healthcare distribution in South Africa was still not comprehensive. Although public healthcare was free for citizens, it was not within the reach of the majority of South Africans. Where it was accessible, the quality of healthcare provided was inferior. There were disparities between the public and private health care systems, and in all nine provinces, most households had difficulty providing health insurance for at least one member (Omilola and Akanbi, 2014). In Kenya, the difference in life expectancy between two regions was 16 years, while doctor patient ratios were 1: 20,700 in the Central Province and 1:120,000 in the North Eastern Province (Owiti, 2014).

In Senegal, there were rural-urban and regional inequalities in access to health infrastructure and skilled personnel, rates of malnutrition, underweight and HIV/AIDS prevalence. Although the country had registered improvements in each of the above areas, these were not 216 enough to bridge the rural-urban gap, even in situations where urban areas were experiencing a noticeable deterioration in access. For example, in 2005, only 2 per cent of people in Dakar took more than 1 hour to access health facilities. By 2011, this figure had increased to 4.88 per cent. While in rural areas the percentage had reduced from 39.65 per cent to 13.98 per cent, it was still more than three times the figure for Dakar (Diene, 2014).

In Ghana, the gap between the rich and the poor with regard to health care access had narrowed because of the introduction of the National Health Insurance Scheme (NHIS). However, there were higher rates of maternal mortality in rural than in urban areas. In addition, children from poor households were twice as likely to die before the age of five as children of the rich were (Osei-Assibey, 2014). Child mortality was also high in Nigeria, especially in the northern parts of the country. There was also evidence that a great majority of Nigerians did not have access to modern medical facilities and skilled medical personnel (Ariyo and Olaniyan, 2014). In Senegal, health care infrastructure and skilled health experts were unequally distributed in favour of urban areas. In addition, malnutrition was more serious in rural than urban areas (Diene, 2014).

\section{Access to other services}

The Senegal study is one of the few that examined access to water and transportation as indicators of social inequalities. The study found a mixed picture. While urban areas were generally better served than rural areas, Senegal had recorded reversals in urban areas. With regard to clean water for example, between 2005 and 2011, there were reversals in Dakar and other urban areas in the percentage of people who took more than one hour to procure water, while the figure for rural areas had stagnated. The situation was the same for transportation and educational facilities, where, in spite of better conditions in urban areas, difficulties had increased in some urban areas (Diene, 2014). This has been attributed to lack of infrastructure, growing urbanization and high rates of rural-urban migration. 


\section{Tsikata: African Inequalities and Structural Transformation}

\section{Political inequalities}

The political inequalities identified in the country studies were mostly based on class, age, gender and ethno-regions. In Kenya, the youth (18-35) were identified as the most politically excluded group in spite of their significant numbers (60 per cent of the population). Ethno-regional inequalities were also serious, and the study provided statistical evidence of the over-representation of certain regions in the cabinet, military, diplomatic service and the public service during periods when presidents from those regions were in power. The figures also showed the gross under-representation of regions of opposition leaders considered hostile to the government (Owiti, 2014). ${ }^{10}$ The study also found that the political elite in Kenya enjoyed the differential application of public policies including economic management tools such as fiscal governance, as well as benefits accruing from office such as parliamentary remuneration and access to development funds. Other instances of elite capture of fiscal governance include the fact that restrictions were lifted on the involvement of public servants in private businesses, and this in turn fuelled patronage politics, corruption, tax avoidance and evasion, and was responsible for decisions such as the suspension of the capital gains tax, which benefitted business sectors dominated by the ruling elite. The passage of the post-electoral violence constitution notwithstanding, the skewed distribution of political office along ethnic lines continues to be a problem in Kenya (Owiti, 2014).

The Mauritius study also found that discrimination was a factor in political inequalities. There was discrimination against people of particular ethnic groups, especially Mauritians of African descent, and certain religious groups. Some members of these groups responded to their discrimination by lobbying for positions in the political system. Other factors fuelling political inequalities were the lack of transparency in political party financing and costly bureaucratic demands on political parties which acted as barriers to organized participation in the political system. ${ }^{11}$ Moreover, opposition parties did not appear to stand a chance of winning elections in
Mauritius. This situation, coupled with high rates of corruption and discrimination, was reflected in the worsening of Mauritius's position on the corruption index (from 53 in 2007 to 43 in 2012), constituting a threat to the country's ability to sustain its democracy (Bunwaree, 2014).

\section{Gender inequalities}

As has become clear in the preceding discussion, within the three domains of inequality, there have been intersecting inequalities linked with class, gender, kinship, ethnicity and geography. This segment highlights some of the findings on gender inequalities in the background paper dedicated to this study and in the seven country studies. This is to illustrate the linkages among the different domains of inequalities. Most of the country studies acknowledged a long history of gender discrimination and resulting inequalities in education, health, politics, employment and land ownership. Global statistics on assets ownership point to women being more constrained than men in acquiring and keeping assets. In relation to land specifically, women are disadvantaged in relation to men in reported land ownership, documentation of ownership, operation, management and decision making (Doss et al., 2013). The Ethiopian study found that the discrimination against women in social and economic spheres had been achieved through oppressive social norms and unequal pay in labour markets. Some of the social norms were so severe that they prevented women in certain ethnic groups from inheriting assets, making independent decisions in asset ownership, and participating in business and other occupations. It had also hampered their access to employment in the formal sectors of the economy (Kedir, 2014). In Nigeria, women did not have the opportunity to own certain categories of land due to the particular form of patrilineal inheritance practised in that country. Similarly, in Kenya, women owned less than 5 per cent of registered lands, and usually faced several institutional and legal obstacles in respect of land and property rights. These deficits have had a negative impact on women's capacity to access the kind of 217 


\section{Development 58(2-3): Thematic Section}

financial services that would significantly support their economic activities (Ariyo and Olaniyan, 2014; Owiti, 2014).

The Ghanaian study found that women earned lower wages than men did, regardless of their education, age and experience. The hourly earnings of women in Ghana were 57 per cent of that of men. In addition, the majority of women were found in non-farm self-employment and private informal jobs where earnings were relatively low, whereas the formal sector, where earnings were higher, was dominated by men. In addition, women did not have control over many of the assets within households. For example, women in some parts of the savannah zone did not have the opportunity to own and control livestock, especially the big ruminants. In other places where they could own livestock, women still needed the permission of their husbands to sell their own livestock and, as such, they did not have absolute control over their assets (Osei-Assibey, 2014). Similarly, women in Mauritius constituted 35 per cent of the labour force, with a vast majority of them in low skilled, low paid and low status jobs (Bunwaree, 2014).

With regard to discrimination against women in the political sphere, Wanjala noted that women's participation in formal political structures and processes where decisions regarding the use of natural resources are made was insignificant. Women comprised 22.9 per cent of members of parliament in sub-Saharan Africa, with countries such as Rwanda leading with 64 per cent, followed by South Africa at 45 per cent, Kenya at 19 per cent, Ghana at 11 per cent and Nigeria having only 7 per cent in the lower houses of parliament (Wanjala, 2014). In Ghana, women were also poorly represented in the executive branch of government, in major public administrative positions, in the judiciary and within local government, all of which are critical sites of adjudication and decision-making with far reaching economic, social and political implications (Tsikata, 2009; Osei-Assibey, 2014). Even in countries with affirmative action measures in place, implementation was sometimes a challenge (Tsikata, 2009). For example, although Mauritius had a protocol for 30 218 per cent representation for women in parliament, it continued not to meet this quota. In 2010, the country achieved 21.4 per cent representation for women in parliament.

Some of the factors that have resulted in the nomination of few women by their political parties were the shrinking potential of female spaces in the face of male-dominated alliances and coalitions, gender biased socialization patterns, lack of financial resources, the "first past the post" electoral system, and the widespread opposition to any form of affirmative action (Bunwaree, 2014). There were also high rates of discrimination against women in Ghana's political sphere, which had resulted in the dominance of male representation in decision-making spaces such as parliament and other public offices. The representation of women in both parliamentary and presidential elections was poor, and progress very slow. This was in spite of the fact that several women were interested in participating in electoral processes (Osei-Assibey, 2014).

Gender-based violence is another marker of gender inequality which very few of the studies discussed. The Mauritius study reported high rates of domestic violence (Bunwaree, 2014). In Ghana, female genital mutilation and the practice of female ritual bondage (Trokosi system), although in decline, were prevalent in particular regions (Osei-Assibey, 2014).

The Kenyan study examined negative responses to inequality, a very pertinent issue in understanding the repercussions of inequalities. The study found that the manipulation of demographic data for economic and political gain was one of the responses to inequalities. In Kenya's devolution programme, revenues to counties were allocated on the basis of their population size. Some counties had therefore increased their population numbers in order to attract higher allocations, and in one case, a county grew from 900,000 to 2.3 million in ten years. Other undesirable responses included political insularity, in which groups that considered themselves disadvantaged only focused on their narrow interests. The study also identified tax evasion and non-compliance, particularly in the informal economy, as an example of negative responses to inequalities of opportunity and access (Owiti, 2014). 


\section{Tsikata: African Inequalities and Structural Transformation}

\section{Development policy interventions and their capacity to address inequalities}

\section{Trajectories of policymaking and programming}

Since the 1980s, African countries have generally pursued several economic stabilization and structural adjustment policies largely aimed at achieving economic growth through economic liberalization and privatization. From the 1990s, several African countries took up political liberalization and institutional reforms to promote good governance, strengthen the institutional base of their economic and social policies and attract foreign direct investment. Multi-party constitutional rule became the dominant form of government, with countries taking up various variations of this system, albeit with different levels of success. Economic liberalization continues to be the bedrock of policymaking and programming in the economic, social and political domains. While the studies did not directly discuss the capacity of economic liberalization policies to address economic, social and political inequalities, the unanimous finding that inequalities have grown in all three domains would suggest that tackling inequality was not a priority for these policies.

From the late 1980s, social safety net programmes designed to give limited attention to some of the deleterious effects of economic liberalization policies on segments of the population replaced the more universalist approach to social policy of the 1960 s and '70s. From the 2000s, tackling poverty became a serious policy concern and the first Poverty Reduction Strategy Papers (PRSPs) were drawn up in several African countries. The first generation of anti-poverty policies were replaced more recently by more ambitious development programmes which can be loosely described as being aimed at structural transformation. Some of these more recent programmes were derived from Continental initiatives such as the New Partnership for Africa's Development (NEPAD) ${ }^{12}$ and its Comprehensive Africa Agriculture Development Programme $(\mathrm{CAADP}),{ }^{13}$ as well as sub-continental policies linked with regional integration agendas.
The trajectory of policymaking described above is captured in several of the country studies. The Nigerian study, for example, identifies twelve programmes between 1982 and 2012, which are a mixture of structural adjustment and privatization programmes (1982-1993), national planning and poverty reduction programmes (2002-2007), and long range plans (2010-2012) (Ariyo and Olaniyan, 2014). This is no different for Senegal (Diene, 2014), Ghana (Osei-Assibey, 2014) and Mauritius (Bunwaree, 2014). Diene has observed that for Senegal, progressively more comprehensive and multi-sectoral programmes have been accompanied by increased spending on social programmes since 2000 (Diene, 2014).

This history of development policymaking has attracted critical commentary. The Nigerian study notes that several of the initiatives were externally conceived and driven, and failed to be domesticated. In their design and implementation, the programmes were not inclusive, did not encourage popular participation and citizens' ownership, and were often short-lived because of regime change. Other shortcomings were the fact that they were implemented with scant regard for particular outcomes and impacts, and lacked a strategic framework to translate them into targets and deliverables. Some failed to include safety nets to mitigate short-term negative impacts and were not designed to address long-term development problems (Ariyo and Olaniyan, 2014). All in all, the results of all the programmes have not been commensurate with their stated objectives. The most important critique of these policies, however, is the observation that they either failed to reduce inequalities or even worsened the problem (Ariyo and Olaniyan, 2014). In the absence of systematic assessments of effects of these policies, it is difficult to attribute particular policies to the rising inequalities in the various domains. However, it is possible to argue that the sum of policies implemented since the 1980s failed to make a dent in the problem of rising inequalities. In the section that follows, we discuss some of the more recent policies and programmes which are common to the country studies. 


\section{Development 58(2-3): Thematic Section}

\section{Recent policies and programmes}

\section{Economic and social development programmes} Poverty Reduction Strategy Papers, which coincided with the MDGs regime, marked a significant shift in economic policy and programming. Both Ghana and Senegal had PRSPs while Nigeria had the National Economic Empowerment and Development Strategy I and II. Mauritius also adopted poverty alleviation programmes and established a Ministry of Social Integration (Bunwaree, 2014). The PRSPs were often accompanied by economic growth programmes, such as Senegal's Accelerated Growth Strategy. The Senegal study argues that while the PRSP had resulted in more people across Senegal being able to access water and electricity, it had failed to address many of the MDGs (Diene, 2014).

The successor programmes to the PRSPs have tended to be more comprehensive and ambitious. For example, Senegal's 2012 National Strategy for Economic and Social Development seeks to improve health and nutrition as well as access to drinking water, support universal education, the eradication of illiteracy and the promotion of national languages, thus addressing the main sectors where social inequalities are more severe. ${ }^{14}$

The Ghana Shared Growth and Development Agenda (GSGDA I, 2010-2013, and II, 2014-2017) is another example of this approach. It includes strategies for macro-economic stability, private sector competitiveness, agricultural modernization, sustainable natural resource management, oil and gas development, infrastructure and human settlements, human development, productivity and employment and transparent, responsive and accountable governance. All these programmes share the fact that they are mostly geared towards economic growth, the enhancement of productivity, and poverty reduction. The reduction of inequalities has, in most cases, not been a policy priority.

\section{Sectoral policies and programmes}

The development programmes under discussion are accompanied by various sectoral development programmes, some related to the real economy e.g. agriculture and employment, and others focusing on social sectors such as social protection.

\section{Social protection}

Social protection programmes in particular have become very popular since the MDGs were instituted. Ethiopia has one of the largest on the African continent, the Productive Safety Net Programme (PSNP). Other countries with similar programmes are Kenya, Mozambique, Malawi and South Africa (Kedir, 2014). Three social protection measures - cash transfer schemes (modelled on similar schemes from Latin America such as Brazil's Bolas Familia), health insurance and youth employment - have been instituted in many African countries, including the case study countries. Ghana for example has adopted measures such as the enrolment of the extremely poor and vulnerable in the National Health Insurance Scheme (NHIS), per-capita grants for schools to cover household education costs, a cash transfer programme known as the Livelihood Empowerment against Poverty (LEAP), a school feeding programme and a National Youth Employment Programme (NYEP) (Osei-Assibey, 2014). Assessments have found that Ghana's LEAP and the NHIS have reached some of the poorest people. However, both programmes do not reach the majority of the poor and have problems with sustainability. While the LEAP is donor-dependent, the NHIS is threatened by small premiums relative to its budget, and the fact that most of the contributions come from payroll taxes, which are inadequate because only a minuscule percentage of the labour force is found in formal work.

In general, social protection interventions face implementation challenges and are limited in scale because of resource constraints, operational deficiencies, and corruption (Osei-Assibey, 2014). Beyond this, social programmes should be judged by their reach and ability to solve multiple problems, including inequalities and socio-economic development challenges. Because they are now largely targeted at the poor, and focus mainly on protection, they are too limited in scope to perform many of the functions of social 


\section{Tsikata: African Inequalities and Structural Transformation}

policy, including support for production and reproduction, redistribution, and social cohesion (ISSER, 2013).

\section{Agricultural policies}

In relation to economic sector policies, agricultural modernization programmes are common across the case studies. For example, the Back to Agriculture Programme (BATA) was instituted in Senegal to deal with unemployment and to encourage participation in agriculture (Diene, 2014). As a means to tackle gender inequalities in agriculture, the Agriculture Transformation Agency (ATA) in Ethiopia established a sector specific programme of gender mainstreaming to promote gender equality in all aspects of their work (Kedir, 2014). While these various efforts have supported smallholders who constitute the majority of Africa's labour force, questions have been raised about their success with tackling inequality in agricultural policies and policy outcomes (Kedir, 2014). Diene (2014) has argued that the BATA programme did not address inequalities arising from employment because the educational system had not prepared people to work in production. Thus, the lack of coordination between policy sectors was undermining the aims and objectives of the programme (Diene, 2014).

\section{Employment policies}

A few countries have programmes to address unemployment. A good example is Senegal's New National Employment Policy (NNEP), which aimed to provide 700,000 new jobs between 2010 and 2015, the National Action Plan for Youth Employment (PANEJ), the National Fund for Youth Employment (FNPJ) and the National Agency for Youth Employment (ANEJ). All these programmes aimed at integrating youth within the labour market and supporting youth-led business projects in agriculture, fisheries, textiles, ICT and tourism (Diene, 2014). Similarly, the government of Ghana designed the National Youth Employment Programme to create jobs for unemployed youth. Targeting particular sectoral problems has become the preferred approach to development issues. In the case of youth unemployment, job creation for young people has not been particularly successful largely because unemployment is not simply a sectoral problem. It requires macro-economic policies and social policies which translate into economic growth that generates decent work in the key sectors of the economy.

\section{Decentralization and regional development} Since the 1990s, there have been renewed efforts in several African countries to tackle rural underdevelopment through decentralization policies. These are aimed at empowering local government entities to deliver basic services to their communities and strengthen subsidiarity in governance. Decentralization has different elements - administrative, political, and fiscal, which point to different degrees in decentralization programmes in different countries. There have been different forms of administrative decentralization - de-concentration, delegation and devolution, the most far-reaching of these being devolution. Kenya's devolution programme is arguably its most important effort to deal with spatial inequalities. The Kenya Constitution provides that a minimum of 15 per cent of government revenue be given to the country's 47 counties. Laws have been passed since then to establish how the revenue will be shared and how counties would receive the revenues, and institutions have been tasked with ensuring that resources meant for the counties have been budgeted and disbursed. There are also arrangements to ensure that, on the basis of their relative poverty, counties receive equalization grants. The Kenya devolution programme is supported by several institutions and programmes. ${ }^{15}$ While these programmes may have improved welfare to some extent, they have been adjudged not to have significantly reduced socio-economic inequalities, either because of pre-existing differences at their initiation, or technical weaknesses, poor prioritization, and elite capture (Owiti, 2014). It remains to be seen the extent to which devolution in Kenya will succeed in reducing inequalities. 


\section{Development 58(2-3): Thematic Section}

Ghana's Savannah Accelerated Development Authority (SADA) is another example of a programme to tackle spatial inequalities, this time between northern and southern Ghana. It aims, through a series of coordinated interventions, to create employment, reform agriculture to strengthen value addition, improve the assets base of poor farmers and invest in irrigation and other technologies. SADA is yet to establish itself as a credible intermediary for northern Ghana's development, has experienced challenges with funding and has had its reputation tarnished by allegations of corruption and mismanagement (Osei-Assibey, 2014).

\section{Legal and institutional reforms}

Legal and institutional reforms have been additional approaches to certain inequalities. For example, to tackle the problem of gender inequality, Ethiopia passed a Family Law Amendment in 2000 to raise the legal age of marriage from 15 to 18 years, give women a greater say in the decisions about marital property, and provide spouses the freedom to work outside the house without obstruction from either spouse. This law allowed girls to stay in school longer and improve their labour market prospects (Kedir, 2014). Mauritius also passed legislation on corporate social responsibility (CSR), making it mandatory for all companies to allocate 2 per cent of their net profits to non-governmental organizations working to improve welfare. As well, the government announced a programme of democratization of the economy. As in all other cases, these policies may have reached a few, but have not addressed the increasing concentration of wealth (Bunwaree, 2014).

Ethiopia also established a Ministry of Women, Children and Youth Affairs and improved the number of seats held by women in its parliament (Kedir, 2014). Similar efforts to tackle gender inequalities have been made in Kenya (see Wanjala, 2014, for details on legal efforts to tackle gender inequalities in Kenya).

In addition to the policies and programmes which are common to several countries in our case studies, there are specific programmes that address particular crises rooted in inequalities.
Kenya's National Accord and Reconciliation Act of 2008 (NARA) is a good example of this. NARA is a political pact among the Kenyan elite to stop political violence, and establish a coalition government to stem the violence in the aftermath of the 2007 elections. ${ }^{16}$ In spite of its challenges, it was an important attempt which yielded a new, more progressive constitution with a bill of rights, affirmative action to address representational inequalities, and devolution (Owiti, 2014). Most importantly, the constitution represented the success of long years of advocacy by certain interest groups, such as the women's movement, to protect themselves against the most overt forms of discrimination, disadvantage and exclusion (Owiti, 2014). The amended constitution notwithstanding, women still face structural barriers such as financial constraints, and a male chauvinist political culture characterized by violence and intimidation. So far, this has largely prevented women from fulfilling the promises of the 2010 Constitution (Owiti, 2014). ${ }^{17}$

The discussion of the state of inequalities in the previous section suggests that the policy and programmatic framework as well as specific macro-economic and sectoral policies have successfully reduced poverty levels in some countries. However, they have failed to stem, and in some cases have been responsible for, rising inequalities over the years. As most of the country studies found, policy and programmatic interventions have focused on tackling poverty, with the reduction in inequality seen as a byproduct of poverty reduction. Cecile Jackson's critique of policies that address women's poverty is instructive in this regard. As she points out, policies that tackle women's poverty do not necessarily address gender inequalities, and in some cases could even worsen them (Jackson, 1996). This lesson can be extended to other inequalities.

In any case, according to at least one country study, the prospects for tackling inequalities at this juncture are not good. Ongoing fiscal consolidation and tight monetary policies aimed at reversing high budget deficits in several countries have proved to be a threat to reducing inequality. In Ghana, for example, measures such as the 


\section{Tsikata: African Inequalities and Structural Transformation}

removal of energy subsidies and the growing debt stock, which is keeping interest rates very high above Africa's average - are worsening poverty and inequality (Osei-Assibey, 2014).

\section{Inequality and structural transformation: comparative experiences and lessons}

What do these policy deficits and persistent inequalities mean for structural transformation? Structural transformation is defined by four processes which are largely economic and demographic: the declining share of agriculture in GDP and employment; rapid urbanization as a result of rural-urban migration; the rise of an industrial and service economy; and a demographic transition from high to low rates of births and deaths. The outcome of these processes is that agriculture would be no different from other sectors in terms of productivity of labour and capital and the location of poverty, and the economy enjoys sustained growth and development because of its diversification and high levels of value addition and productivity of all economic activities (Timmer, 2012).

On the basis of these criteria, most African countries have not yet experienced structural transformation. Instead, they have experienced rapid labour migration out of a stagnating agricultural sector into an informal services sector with even lower productivity levels, which therefore does not contribute significantly to overall economic productivity (Ariyo and Olaniyan, 2014). While the Ethiopia study argues that structural change has taken place in Ethiopia because the service sector has overtaken agriculture, the authors point out that its service sector is predominantly informal and unprotected, and women are in the majority of those who operate in it. As well, it is characterized by low returns, low technology, low productivity, and is unable to transform the lives of those who work in it. The study therefore recommends state intervention to provide productive capital and support the formalization of the sector (Kedir, 2014).

The nexus between inequality and structural transformation is discussed in two ways in the UNECA study. ${ }^{18}$ The first is the impact of inequality on structural transformation, while the second is the impact of structural transformation on inequality. In relation to the first, the study argues that in the absence of robust empirical and theoretical data about the impact of inequality on structural transformation, this can only be inferred from the literature that links inequality and economic growth. The majority of those studies argue that inequality has a negative effect on growth. This is because initial inequality affects the ability of economic agents to participate effectively in economic activity and therefore results in the misallocation or under-utilization of resources. This will slow the pace of growth and possibly of industrialization and structural transformation (Armah et al., 2014).There are at least three channels through which inequality affects growth. First, initial inequality in resource endowment affects the ability of the poor to borrow for productive investments from imperfect capital markets. Thus, capital market imperfections not only perpetuate inequalities, but also lead to the under-utilization of resources, low investment, low pace of growth and industrialization. Secondly, such inequality has adverse effects on investments in human capital and social reproduction, which creates a vicious cycle of low human capital development, high fertility and poverty. A third channel is how the low incomes of the majority of the population have an adverse effect on the size of the domestic markets (Armah et al., 2014).

With regard to the impact of structural transformation on inequality, the UNECA study argues that African policymakers can benefit from learning about conditions under which structural transformation reduced inequalities while generating wealth. The study therefore compares and contrasts the experiences of countries that achieved reductions in inequalities and those that did not. The report notes that in Western Europe and North America, industrialization played an important role in structural transformation by increasing the demand for certain skills and creating the need for educational reforms to facilitate labour intensive production. These reforms were associated with increases in workers' productivity, incomes, and assets 223 


\section{Development 58(2-3): Thematic Section}

accumulation, thus leading to a gradual decline in inequalities. In the case of Taiwan and South Korea, economic growth was not associated with rising inequalities in the early stages of their development. This is because land reforms and improved agricultural extension services contributed to increased agricultural productivity, leading to poverty reduction. This suggests that growth in both industrialization and agriculture reduced inequalities.

In the case of Latin America, import substitution industrialization has been credited with contributing significantly to reducing inequality. Brazil and Mexico enjoyed rapid economic growth, which increased employment opportunities until the industrial and debt crises of the 1980s resulted in the collapse of import substitution industries, a reduction in the size of the unionized working class and negative growth. This then resulted in increased inequalities.

More recent analysis about the relationship between inequalities and structural transformation has argued that while structural transformation can reduce absolute poverty, it is often accompanied by rural-urban and regional inequality, and therefore it is important to manage the transformation to control the increase of disparities. China illustrates this situation in undergoing transformation while remaining largely unequal. This is in spite of its enviable growth record since the 1980s and progress in poverty reduction, as a result of agricultural and land reforms which gave farmers more space. While this has achieved a more equitable distribution of income, the adverse effects of trade and financial liberalization have resulted in increased income inequalities between rural and urban areas. Better-off industry workers were more heavily represented in urban areas. Similarly, in India, while the information technology revolution resulted in economic growth and reduced poverty, the skill intensive nature of the services sector and its small share of employment has increased income inequality (Armah et al., 2014).

In Malaysia, privatization and liberalization in the mid-1980s were associated with rising inequality. In order to keep exports competitive,

224 Malaysia opened up to foreign workers to drive wages down. This worsened income inequality, a situation ameliorated by affirmative action in favour of indigenous Malaysians. The result was a reduction in inter-ethnic income inequality. This is now being reversed by Malaysia's recent shift to capital-intensive production, which has driven up the wages of a small segment of workers.

Russia, on the other hand, had a different experience of inequalities. In the socialist era, industrialization went hand in hand with low levels of inequality because of the emphasis on the production of food and consumer goods. The overthrow of this system and the re-introduction of market liberalization resulted in de-industrialization, price rises, and the collapse of real wages in the agricultural and manufacturing sectors. This resulted in rising income inequalities worsened by energy becoming the leading sector of the Russian economy. The capital intensiveness of the sector and its demand for highly skilled highly paid labour created enclaves that drove up income inequalities.

In the Nordic countries, centralized pay negotiations, unionization, the collective management of resources, progressive taxation and universal social security systems kept inequalities at bay, even in the 1980s and 1990s, when many countries were experiencing rising inequalities. Other studies have identified the central role of the developmental state and governments in driving change through long-term planning (Kedir, 2014).

The cases discussed above and the limited experiences structural transformation in Africa are instructive. South Africa and Kenya, two of the most industrialized countries in Africa, did not undertake progressive land redistribution. The Ethiopia case complicates the discussion of land redistribution. Ethiopia's land redistribution, which took place in the 1970s, appears not to have positively affected its wealth inequality, nor has it transformed agriculture or increased agricultural productivity in Ethiopia (Kedir, 2014). The lesson is that transformation - characterized by the predominantly informalized, low returns, low technology, low productivity service sector overtaking agriculture in its contribution to 


\section{Tsikata: African Inequalities and Structural Transformation}

GDP - which has occurred in Ethiopia, Ghana, Senegal and other countries, does not reduce poverty and inequality and transform the lives of people, even if it is optimistically referred to as structural transformation (Kedir, 2014).

From the foregoing, it is clear that different countries have experienced different interactions between structural transformation and inequalities, with a range of factors in a complex interplay with the initial conditions of a country to determine outcomes. Countries need to determine the kind of transformation they wish to pursue, understand what is required to achieve this, and apply measures that would ensure successful transformations that also reduce inequalities.

\section{Toward economic structural transformation and equitable and sustainable societies in Africa}

This review essay has a number of messages. The first is that inequalities are not an inevitable result of economic growth or structural transformation. They are driven by history and initial conditions, current policies and inactions. Therefore, they can be solved by policies that alter initial conditions and aim to reduce inequalities. In this connection, an important message is that economic growth should be driven by those sectors that have the best possibilities for backwardforward linkages and generate high quality employment. Growth that is dependent on natural resource extraction and services with very limited backward and forward linkages with agriculture, has not been pro-poor or inclusive. In other words, who benefit from economic growth depends on the drivers of growth, the quality of growth, and its distributional effects. Therefore, economic growth, though necessary, is not sufficient to bring about the social and economic transformation that reduces poverty and inequality in its various dimensions.

Secondly, inequalities which are found in three broad domains (economic, social and political) and on several axes (class and occupation, gender, race, ethnicity, generation and space - region; rural urban; agro-ecology) are interlinked and reinforce each other. At the same time, progress in reducing inequalities in one domain does not necessarily translate into progress in another domain. Thus tackling inequalities is a complex task, particularly in a period where dominant policy choices deepen rather than address inequalities.

While economic, social and political inequalities are common to all countries, how particular inequalities present themselves depends on the structure of each country's economy, its social structure and political systems as well as policy choices. This implies that while some policies may work in all countries, policy details have to take the specificities of each country into account. A related finding is that inequalities in all three domains are growing across Africa between rural and urban areas, between regions within a country, between occupational groups, ethnic and racial groups, between the general population and young people, and between men and women. This is in spite of economic and social policies that are geared towards tackling poverty and related developmental challenges. Part of the problem is that poverty and inequality are not the same and policies directed at reducing poverty will not necessarily reduce inequalities and vice versa. This implies that policies have to deliberately tackle inequalities, a departure from the anti-poverty measures that were considered a proxy for addressing inequality.

Social policy continues to be of vital importance to reducing inequalities. However, its current focus on social protection needs to be expanded in scope to support production and redistribution of the benefits of growth and should be funded by states to reduce donor dependence. Another social policy recommendation is the equal distribution of quality physical infrastructure in order to ensure the more even spread of investments to reduce spatial inequalities. In addition, there were recommendations of investments in education to boost skills across the economy, land redistribution and farmers' training programmes. Another important recommendation was to support informal sector trade and agriculture to reduce youth unemployment.

Paying attention to inequalities in particular sectors is important. For example, several studies emphasized the creation of productive 


\section{Development 58(2-3): Thematic Section}

employment through improvements in labour market access and the quality of jobs, rather than income distribution, as key to reducing inequalities and promoting structural transformation. While direct attention to particular sectoral inequalities had achieved reductions in poverty and inequalities, contradictions between economic and social policy agendas made such gains unsustainable. This points to the need to ensure that both economic and social policies, as well as macro and sectoral policies, work in tandem towards the goal of reducing inequalities, and draw synergies from each other.

With regard to the relationship between inequalities and structural transformation, lessons from other countries were instructive. Those countries which had strong social policies to accompany their processes of structural transformation whether these were land reforms, redistributive policies or investments in sectors with substantial proportions of the labour force, tended to control rising inequality. The lesson learned here is twofold: it identifies which policy options would support structural transformation and which ones would ensure that inequalities are reduced.

A key demand from several studies was a fundamental change in the culture of policymaking to ensure the full participation of all citizens and the coordination and alignment of the numerous economic and social policies, including their systematic evaluation.
Last but not least, due to grave data challenges, few of the studies were able to comprehensively review the situation with inequality and structural transformation, determine the most effective policy and programmatic approaches, and monitor their implementation. This is an urgent question that requires an Africa-wide approach to data collection to reduce costs and ensure that decisions are based on high quality data. Related to this, there is the need for clarity on the kind of data and indicators to be collected as a priority. For example, it would be important to determine which inequality index to adopt and which indicators to use for the different domains of inequality. Omissions in data collection, such as the total income distribution between labour and capital, would then receive full attention.

This essay, though limited in scope and challenged by incomplete data, provides a preliminary basis for setting an agenda of research and advocacy to support African and country efforts to tackle the deepening inequalities and achieve structural transformation.

\section{Acknowledgments}

I am grateful to Sylvia Marfo for research assistance and to Bartholomew Armah, Alex Cobham, Yao Graham, Takyiwaa Manuh and Stefano Prato for very useful comments on an earlier draft of the article. 


\section{Tsikata: African Inequalities and Structural Transformation}

\section{Notes}

1 This is in contrast with West Africa, where the Gini coefficients in Côte d'Ivoire, Mali and Niger dropped between 7 and 10 points within similar periods. Looking at Africa as a whole, out of 35 African countries with data, 37.1 per cent experienced an increase in income inequality while 54.3 per cent experienced a decline between 1990 and 2012. In Asia, a higher percentage of countries experienced rising inequalities, while in Latin America, there were net reductions in inequality in this period (Armah et al., 2014).

2 While these statistics are stylized, and it is unclear what precisely these assets and wealth consist of, we assume that that they measure some of the components of wealth, income and assets we discuss in this article.

3 In both the Common African Position on the post 2015 Development Agenda and the African Union Agenda 2063. African countries have prioritized structural economic transformation as a strategy for inclusive, sustained and sustainable development (Armah et al., 2014).

4 Africa-wide Conference on 'Inequalities in the Context of Structural Transformation', which was held in Accra, Ghana, on 28-30 April 2014. Under the leadership of the Government of Ghana (with the facilitation of the National Development Planning Commission), the Conference was organized by the following institutions (in alphabetical order): Council for the Development of Social Science Research in Africa (CODESRIA), Institute of Statistical, Social and Economic Research (ISSER), Society for International Development (SID), Third World Network Africa (TWN-A), United Nations Children's Fund (UNICEF), United Nations Development Programme (UNDP), United Nations Economic Commission for Africa (UNECA), United Nations Millennium Campaign (UNMC).

5 South Africa and Kenya are at one extreme with Ethiopia and Mauritius at the other end, while Senegal, Ghana and Nigeria are in the middle.

6 These include increased savings by rich people resulting in increased investment, and the motivation of poor people to work harder to increase growth and discourage the use of taxation to address income inequality (Kedir, 2014).

7 Assets have been defined as the stock of resources such as savings, vehicles, real estate, mortgages, mutual funds, stocks and bonds. Armah et al. point out that assets are key indicators of wealth and poverty, provide a more reliable and stable measure of wealth than income and are an indicator of social status. They also can be used to access goods and services in place of money (Armah et al., 2014).

8 The Atkinson Index is a welfare-based measurement of inequality. See Kedir (2014) for a discussion of its parameters.

9 Factors accounting for this situation include the history of neglect of northern Ghana dating back to the colonial period, the extreme nature of droughts, flooding and windstorms, the dependence of most of the inhabitants on a single source of provisioning, and the non-inclusive governance practices and dereliction of duty by some officials (Osei-Assibey, 2014).

10 Ethno-regional inequalities were a factor in Kenya's electoral violence of $2007 / 08$, fuelled by the belief that political power enables the ethnic group of the President of the Republic to enjoy unprecedented patronage and exclusive access to economic and political resources. These include control over institutions and decisions that affect welfare, such as employment and public contracts (Owiti, 2014).

11 For example, the requirement that political parties submit a balance sheet to the registrar of associations or the Mauritius Revenue Authority requires expenditures, which add to the cost of the political system.

12 An economic development programme of the AU adopted at the 37th Session of the Assembly of Heads of States and Governments in 2001.

13 Adopted as a NEPAD programme in 2003 to help Africa reach a higher path of economic growth through agriculture - led development which eliminates hunger, reduces poverty and food insecurity and enables the expansion of exports.

14 In addition, the Document of Economic and Social Policy, the National Strategy for Economic and Social Development (2013-2017) and the Plan for Emerging Senegal (2014) are to increase wealth, welfare and social demand; to tackle unemployment, gender inequality, and promote social protection and sustainable development.

15 These include the District focus for Rural Development (DFRD), the Local Authority Transfer Fund (LATF), Safety Net Programs, the Anti-Poverty Commission, the Gender Commission, The Constituencies Development Fund (CDF), Free Primary Education (FPE) and Decentralised Public Health Services (Owiti, 2014).

16 Some of the initiatives under NARA were aimed at addressing horizontal political, social and economic inequalities. These included a comprehensive constitutional review, land reform and poverty alleviation.

17 In a few cases, e.g. cabinet secretaries, women occupied 30 per cent of positions. However, as ethno-regional patronage still revolves around men, it was reported that men from certain ethnic groups felt aggrieved that 


\section{Development 58(2-3): Thematic Section}

women were appointed to the only cabinet secretary positions given to their communities. This also points to some of the challenges of implementing affirmative action designed to tackle multiple sources of inequalities simultaneously (Owiti, 2014).

18 As this is the only study that theorizes structural transformation in any detail, this section relies mainly on its insights.

\section{References}

Alesina, Alberto and Dani Rodrik (1994) 'Distributive politics and economic growth', The Quarterly Journal of Economics, 19(2): 465-490.

Ariyo, Ademola and Olanrewaju Olaniyan, (2014) 'Inequalities in the Context of Structural Transformation: Evidence from Nigeria', paper prepared for Pan-African Conference on Inequalities in the Context of Structural Transformation held in Accra, Ghana 28-30 April 2014. Abridged version of the paper published in Development 57(3-4): 531-539.

Armah, Bartholomew, Mama Keita, Aissatou Gueye, Valerio Bosco, Judith Ameso and Ziv Chinzara (2014) 'Structural Transformation for Inclusive Development', a Background Paper for the Pan-African Conference on Inequalities in the Context of Structural Transformation, Accra, Ghana, 28-30 April 2014. Abridged version of the paper published in Development 57(3-4): 438-451.

Berg, Andrew, Jonathan D. Ostry, and Jeromin Zettelmeyer (2012) 'What makes growth sustained?', Journal of Development Economics, 98(2): 149-166.

Bunwaree, Sheila (2014) 'The Fading Developmental State - Growing Inequality in Mauritius', paper presented at the Pan-African conference on Inequality in the Context of Structural Transformation Accra, Ghana, 28-30 April 2014. Abridged version of the paper published in Development 57(3-4): 578-590.

Credit Suisse (2013) 'Global Wealth Report 2013', Zurich.

Diene, Mbaye (2014) 'Inequalities in the Context of Structural Transformation: Senegal Country Case Study', paper for the Pan-Africa Conference on Inequalities in the Context of Structural Transformation presented in Accra Ghana, 28-30 April 2014. Abridged version of the paper published in Development 57(3-4): 540-546.

Doss, Cheryl, Chiara Kovarik, Amber Peterman, Agnes R. Quisumbing and Mara van den Bold (2013) 'Gender Inequalities in Ownership and Control of Land in Africa'. IFPRI Discussion Paper 01308.

Fox, Louise and Obert Pimhidzai (2011) 'Is Informality Welfare-Enhancing Structural Transformation? Evidence from Uganda', World Bank Policy Research Working Paper No. 5866.

Institute of Statistical, Social and Economic Research (2013) Overview, Ghana Social Development Outlook 2012; Legon: ISSER.

Jackson, Cecile (1996) 'Rescuing Gender from the Poverty Trap', World Development 24(3): 489-504.

Kedir, Abbi M. (2014) 'Inclusive growth and Inequalities in the Context of Structural Transformation: Ethiopia' paper for the 'Pan-African Conference on Inequalities in the Context of Structural Transformation' presented in Accra, Ghana, 28-30 April 2014. Abridged version of the paper published in Development 57(3-4): 512-520.

Kenya National Bureau of Statistics and Society for International Development (2013) Exploring Kenya's Inequality: Pulling Apart or Pooling Together?, Nairobi: SID.

Kuznets, Simon (1955) 'Economic growth and income inequality', American Economic Review, 45(1): 1-28.

Lee, Caroline W., Michael Mcquarrie and Edward Walker (eds.) (2015) Democratizing Inequalities: Dilemma of the New Public Participation, New York: New York University Press.

Lee, Sangheon (2015) 'Kuznets after the end of the Kuznets Curve, Global Labour Column', Number 194, Corporate Strategy and Industrial Development (CSID), February.

Mkandawire, Thandika (2013) 'Beyond Recovery', Aggrey-Fraser-Guggisberg Memorial Lecture, 17-19 ${ }^{\text {th }}$ April, University of Ghana. http://www.orid.ug.edu.gh/aggrey-fraser-guggisberg-lectures.

Neckerman, Kathryn. M. (2004) Social Inequality, New York: Russel Sage Foundation.

Okun, Arthur Melvin (1975) Equality and Efficiency: the Big Trade-off, Washington, DC: Brookings Institution Press.

Omilola, Babatunde and Olusegun A. Akanbi (2014) 'The Dynamics and Drivers of Social and Economic Inequalities in South Africa', paper for the Pan-African Conference on Inequalities in the Context of Structural Transformation presented in Accra, Ghana, 28-30 April 2014. Abridged version of the paper published in Development 57(3-4): 559-577. 


\section{Tsikata: African Inequalities and Structural Transformation}

Osei-Assibey, Eric (2014) 'Pan-African Conference on Inequalities: Country Paper on Ghana', paper for the PanAfrican Conference on Inequalities in the Context of Structural Transformation presented in Accra, Ghana, 28-30 April 2014. Abridged version of the paper published in Development 57(3-4): 521-530.

Owiti, Jeremiah (2014) 'Kenya Country Case Study', paper for the Pan-African Conference on Inequalities in the Context of Structural Transformation presented in Accra Ghana, 28-30 April 2014. Abridged version of the paper published in Development 57(3-4): 547-558.

OXFAM (2014) Working for the Few: Political Capture and Economic Inequality, OXFAM Briefing Paper, Oxford.

Persson, Torsten and Guido Tabellini (1994) 'Is inequality harmful for growth?', American Economic Review, 84(3): 600-621.

Society for International Development (SID), (2004) 'Pulling Apart: Fact and Figures on Inequality in Kenya', Nairobi: SID.

Timmer, Peter (2012) 'The Mathematics of Structural Transformation', Thematic Research Note 02, West and Central Africa Office (WCAO), International Food Policy Research Institute (IFPRI).

Tsikata, Dzodzi (2009) 'Affirmative Action and the Prospects for Gender Equality in Ghanaian politics, Abantu', Accra: Women in Broadcasting and the Friedrich-Ebert-Stiftung.

UNDESA (2013) Inequality Matters, Report on the World Social Situation, 2013.

Wanjala, Bernadette M. (2014) 'Gendered Asset Inequalities in Africa', paper for the Pan-African Conference on Inequalities in the Context of Structural Transformation presented in Accra, Ghana, 28-30 April 2014. Abridged version of the paper published in Development 57(3-4): 472-480. 